\title{
Entrepreneurship
}

Jul a Dez $2021-$ v.5 - n.2

ISSN: 2595-4318

This article is also available online at: www.sustenere.co

\section{A presença virtual como forma de melhorar o relacionamento com o cliente}

Este artigo tem por objetivo analisar o impacto das ações relacionadas a presença virtual das empresas, nas empresas participantes do programa Agentes Locais de Inovação, da Região de Guarulhos - São Paulo, atendidas pelo presente autor. Além da pesquisa bibliográfica, foi realizado trabalho de campo com as empresas, formulando junto aos empresários planos de ação voltados para a Dimensão de Relacionamento com o Cliente, a fim de que, fosse possível coletar dados do Diagnóstico do Radar de Inovação para auxiliar nas conclusões. Os resultados obtidos no ciclo 0 apontaram que a maioria das empresas tem grau baixo ou médio de inovação na Dimensão de Relacionamento com o cliente e que não tem uma grade preocupação com a presença virtual da empresa. Tendo essa informação como base, foram sugeridas as ações de criação/reformulação do site. Os resultados demonstraram que as empresas que possuíam grau baixo ou médio no Radar da Inovação tiveram subiram de nível após a conclusão da ação, e as que já tinham um grau alto conseguiram se manter no mesmo.

Palavras-chave: Relacionamento; Cliente; Marketing; Digital; Sites; Inovação; Programa ALI.

\section{Virtual presence as a way to improve customer relationships}

This article aims to analyze the impact of actions related to the virtual presence of companies, in companies participating in the Local Innovation Agents program, in the Region of Guarulhos - São Paulo, attended by the present author. In addition to the bibliographical research, fieldwork was carried out with the companies, formulating action plans with the entrepreneurs focused on the Customer Relationship Dimension, so that it was possible to collect data from the Innovation Radar Diagnosis to assist in the conclusions. The results obtained in cycle 0 indicated that most companies have a low or medium degree of innovation in the Customer Relationship Dimension and that they are not highly concerned with the company's virtual presence. Based on this information, actions to create/reform the site were suggested. The results showed that companies that had a low or medium level in the Innovation Radar had leveled up after the completion of the action, and those that already had a high level were able to maintain the same level.

Keywords: Relanshionship; Client; Marketing; Digital; Innovation; ALI Program.

Topic: Teoria Geral da Administração

Reviewed anonymously in the process of blind peer.
Received: 11/07/2021

Approved: 25/09/2021

Chrystopher William Montenegro

Faculdade Anhanguera de Guarulhos, Brasil

http://lattes.cnpq.br/7199747527423678

http://orcid.org/0000-0003-0298-160X

montenegro.alisp@gmail.com

Referencing this:

MONTENEGRO, C. W.. A presença virtual como forma de melhorar o relacionamento com o cliente. Entrepreneurship, v.5, n.2, p.1-9, 2021. DOI: http://doi.org/10.6008/CBPC2595-4318.2021.002.0001 


\section{INTRODUÇÃO}

O mercado é cada vez mais competitivo e dinâmico ao longo dos anos. As mudanças de comportamento, padrões culturais e o surgimento cada vez maior de novas tecnologias, impõe um ritmo muito forte de nascimento de novos negócios, bem como, novas formas de se trabalhar e divulgar negócios já tradicionais. Dentro desse turbilhão de mudanças está a oportunidade de inovação. Ela pode ser fundamental para alavancar os negócios ou até mesmo ser usada em uma estratégia de sobrevivência, especialmente em momentos delicados quando a economia é instável e os padrões de consumo diminuem por circunstâncias diversas. As pequenas empresas - EPPs, sofrem constantemente com essas mudanças e precisam se apoiar na Inovação para continuar gerando negócios e se manterem competitivas.

Essa realidade abriu portas para o surgimento do Programa Agentes Locais de Inovação -ALI. Tal programa é uma pareceria entre o Serviço Brasileiro de Apoio às Micro e Pequenas Empresas - Sebrae e o Conselho Nacional de Desenvolvimento Científico e Tecnológico - CNPQ. O Programa tem como objetivo estimular a prática continua de ações de inovação nas empresas, criando assim, uma cultura interna de inovação. Em campo, o trabalho desenvolvido inclui a aplicação de diagnósticos, como o Radar de Inovação, por exemplo, que será usado nesse artigo para medir os resultados.

A coleta de dados do Radar de Inovação, na Dimensão Relacionamento com o Cliente, e a pesquisa bibliográfica que fará uma revisão da literatura sobre os temas Inovação, Marketing Digital e Relacionamento com o cliente, formam a metodologia aplicada no presente artigo.

\section{REVISÃO TEÓRICA}

\section{Inovação}

A inovação é um conceito que sofreu alterações na sua percepção de acordo com o tempo. Antes a inovação era facilmente associada apenas a inovação tecnológica, o que sugeria que, a inovação seria sempre algo de um investimento muito alto e radical.

O manual de Oslo contribui para uma melhor interpretação do que é inovação ao caracteriza-la como "a implementação de um produto (bem ou serviço) novo ou significativamente melhorado, ou um processo, ou um novo método de marketing, ou um novo método organizacional nas práticas de negócios, na organização do local de trabalho ou nas relações externas".

Tendo como base esse conceito é possível entender que a inovação algo que está plenamente ao alcance das pequenas empresas, não sendo de uso exclusivo das grandes corporações. Mais do que disponível, a inovação é necessária nos pequenos negócios, seja para se manter competitivo ou para buscar espaço no mercado, ou seja, "as empresas inovam ou para defender suas posições competitivas ou em busca de uma vantagem competitiva".

Seguindo a mesma linha de raciocínio, Silva et al. (2012), caracteriza a inovação como "um processo de mutação industrial que incessantemente revoluciona a cadeia de valor", ou seja, além de ser um instrumento para que as empresas se mantenham competitivas, a inovação também mantém o mercado 
dinâmico e aquecido com a constante agregação de valor que proporciona.

A inovação quando analisada em caráter global, como nos mostra o artigo de Rainatto et al. (2020) não se mede apenas pela quantidade de recurso investido gerando patentes e publicações acadêmicas, mas sim pela interação com o usuário final do processo inovador.

Alterando a competitividade da empresa e o mercado, como citado acima, a inovação tem impacto direto no cenário econômico, uma vez que, segundo Schumpeter (1934), "inovações radicais provocam grandes mudanças no mundo, enquanto inovações 'incrementais' preenchem continuamente o processo de mudança". Além de contribuir para a melhor interpretação do real significado da inovação, o Manual de Oslo mostra que a inovação pode ser dividida em 4 tipos: Produto, Processo, Marketing e Organizacional.

Além da divisão por tipos, a Inovação também pode ser fragmenta em dimensões, para ser mais exato, em 13 dimensões, conforme o instrumento Radar da Inovação. O Radar da Inovação, desenvolvido por Bachman e Destefani, analisa as seguintes dimensões: Oferta; Plataforma; Marca; Clientes; Soluções; Relacionamento; Agregação de Valor; Processos; Organização; Cadeia de fornecimento; Presença; Rede; Ambiência Inovadora. Dentro dessa ferramenta, a Dimensão de Relacionamento é a que será utilizada para avaliar as inovações a serem tratadas no presente artigo.

\section{Dimensão relacionamento com o cliente}

As diversas mudanças ocorridas no século XX impactaram em mudanças no consumo: as pessoas deixaram de consumir somente produtos e passaram também a consumir experiências. Anteriormente, os clientes elegiam os produtos que melhor atendiam suas necessidades baseados em cor, forma, tamanho, desempenho e preço. Hoje, após o desenvolvimento do setor de serviços, as relações de consumo passaram a ser ditadas por este setor, tornando evidente a importância dos aspectos intangíveis nas escolhas dos clientes, tais como emoções e sentimentos. Sugere-se que surgiram ofertas de "experiências", que se distinguem pela vivência do cliente de um momento único (FREIRE, 2008).

O presente artigo pretende demonstrar a importância do Marketing Digital, através de sites bem estruturados e completos, como uma poderosa forma de melhorar o relacionamento com o cliente.

O Radar da Inovação, já citado no subparágrafo anterior, tem uma dimensão especifica para avaliar o Relacionamento com o cliente. A Dimensão Relacionamento leva em conta a experiência que o cliente tem com a empresa e analisa as formas que a empresa cria para interagir com os clientes.

Nessa dimensão é possível apontar a criação/reformulação de sites como uma ação que altera a experiência com do cliente com a empresa.

\section{Marketing de relacionamento}

O Marketing de relacionamento é o responsável por deixar a relação com o cliente mais agradável possível através da busca pela satisfação do mesmo, afinal, como conceituou Kotler (1998), o Marketing é "a atividade humana dirigida para a satisfação das necessidades e desejos, através dos processos de troca" (KOTLER, 1998). 
Nickels et al. (1999) ponderam que à primeira instância o marketing de relacionamento pode ser considerado como a atração, manutenção e o aumento do relacionamento com os clientes. Desta a forma, a atração de novos clientes se coloca como uma etapa, que tem por objetivo final fortalecer os relacionamentos, transformando clientes indiferentes em leais.

Kotler (1998), aponta para a necessidade de conservar um relacionamento constante com os clientes, a fim de monitorar as suas experiências de consumo. A esquematização dessas impressões por intermédio dos relatos dos próprios clientes é o que resulta em uma melhoria do desempenho organizacional. Conhecer essas impressões é fundamental para desenvolver relacionamentos firmes e longínquos que podem impactar não só na retenção de clientes, como também, na prospecção de novos.

Pride et al. (2001), ressaltam que, a confiança está baseada na interação e no relacionamento sólido, e, para que isso ocorra, é essencial que as empresas entendam e correspondam às necessidades dos clientes, afinal, um cliente insatisfeito tende a perder a confiança no relacionamento e buscar um concorrente que supra essa necessidade.

Trazendo esse conceito para o cenário das pequenas empresas, é correto supor que, o Marketing de Relacionamento tem papel fundamental de apresentar a empresa no mercado de forma a cativar e seduzir os clientes, bem como, fidelizar os mesmos.

Cativar novos clientes e fidelizar os clientes antigos pode implicar diretamente na manutenção ou aumento do faturamento de uma empresa. No caso das empresas de pequeno porte que possuem uma carteira de clientes menor, e consequentemente, um faturamento também menor, esse tipo de Marketing se faz mais do que necessário para manter a competitividade. A ideia desse tipo de Marketing é criar e cultivar relações fortes e duradouras com os seus clientes.

\section{Marketing digital}

O Marketing Digital é uma consequência das constantes evoluções da sociedade e do frequente aumento de novas tecnologias.

O mundo digital com suas frequentes mudanças e atualizações, ganha cada vez mais espaço, atenção e repercussão da sociedade de uma forma geral e não é diferente quando se trata do mercado. 0 ambiente digital afeta muito o mercado e os padrões de consumo, afinal, "o consumidor mudou com a tecnologia e a tecnologia mudou com o consumidor" (VAZ, 2014).

Em um estudo proposto por Andrade et al. (2019), a interação do marketing digital com a inovação trazida pela Inteligência artificial, evidenciou em como as mídias digitais aplicadas ao mercado tem proporcionado um resultado de entrega efetiva de comunicação aos usuários finais, mensurando e subsidiando a tomada de decisão de se caminhar pela Inovação em marketing Digital.

Essa importância real que o Marketing Digital tem nos negócios aponta para uma necessidade de que as empresas estejam presentes nesse ambiente, através das redes sociais e também de sites bem estruturados. 


\section{METODOLOGIA}

Para alcançar o propósito do presente artigo que é mensurar o impacto das ações de relacionamento com o cliente nas empresas estudadas, após a propositura dessas ações mediante necessidade identificada com os empresários e apontada no diagnóstico realizado, o método utilizado foi a pesquisa exploratória, cuja técnica aplicada foi a coleta de dados do questionário Radar de Inovação.

Para desenvolver o trabalho de campo cerca de cento e cinquenta empresas foram contatadas pelo autor, no período de julho de 2013 a agosto de 2014 para participar do programa. Dessas, quarenta aderiram ao programa e foram submetidas ao diagnóstico Radar de Inovação. Para o presente artigo, foi utilizada a amostra de $25 \%$ sobre o total de empresas aderidas.

O diagnóstico Radar de inovação foi aplicado com as dez empresas que representam a amostra desse artigo. Os resultados da primeira aplicação desse Diagnóstico são chamados de T0 (Tempo zero), que faz referência ao momento em que a empresa se encontra, visto que, o Radar de Inovação do T0 é o momento em que as ações ainda nem mesmo foram propostas.

Após a aplicação do Radar de Inovação T0 é apresentado à empresa o relatório de devolutiva. Tratase de um documento que traz a pontuação do radar de inovação em todas as suas dimensões e também um gráfico que mostra visualmente a pontuação atual em comparação com a pontuação máxima e que permite comparação com as pontuações obtidas posteriormente nos próximos ciclos subsequentes ao T0, denominados $\mathrm{T} 1$, $\mathrm{T} 2$ e T3.

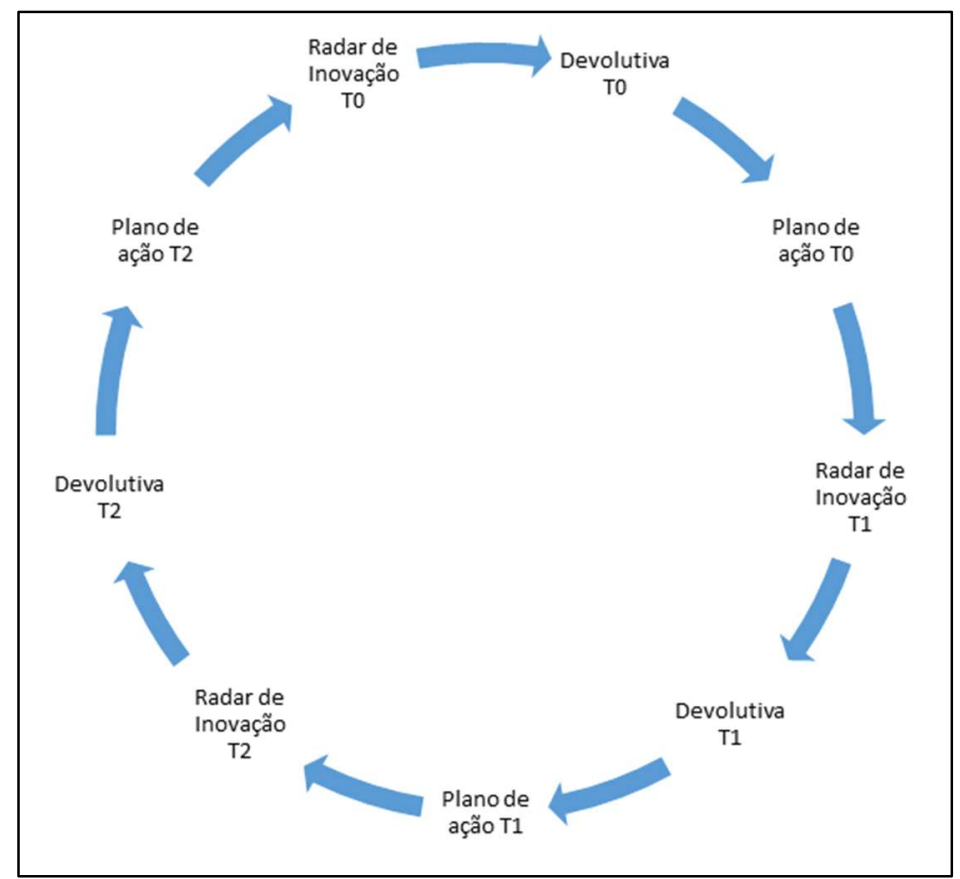

Figura 1: Fluxo da metodologia de coleta de dados.

Com base nos resultados dessa primeira devolutiva é montado junto ao empresário um Plano de Ação, com propostas de ações para solucionar problemas e deficiências apontadas.

Após a implementação das ações, ocorre a mudança de ciclo passando de T0 para T1, T1 para T2, e assim por diante. No novo ciclo é aplicado novamente o Diagnóstico Radar da Inovação para mensurar o 
impacto das ações realizadas no ciclo anterior e mensurar o impacto das mesmas em termos de pontuação.

No fluxograma a seguir é possível visualizar a estrutura e as etapas desse processo:

O processo do Programa Ali, exemplificado acima, vai obrigatoriamente até o ciclo 3, visto que é necessário cumprir obrigatoriamente quatro ciclos, mas pode ir até o ciclo 4, caso haja tempo hábil para realizar as ações e seja da vontade do empresário continuar até esse ciclo.

Nesse fluxograma o processo é apresentado até o ciclo 2, apenas, haja visto que, para a coleta de dados a que se pretende analisar não foi necessário apontar os dados dos ciclos 3 e 4 .

No presente artigo, todas as empresas tiveram a ação a ser estudada proposta no Plano de ação do ciclo T0, no entanto, a conclusão da ação não aconteceu no mesmo ciclo para todas, de forma que, algumas a concluíram no T1, outras no T2, conforme mostram demonstram a quadro 1 e as figuras 2 e 3 abaixo.

Quadro 1: Dimensões do Radar de Inovação.

\begin{tabular}{|l|}
\hline Dimensões da Inovação \\
\hline A - Dimensão Oferta \\
\hline B - Dimensão Plataforma \\
\hline C - Dimensão Marca \\
\hline D - Dimensão Clientes \\
\hline E - Dimensão Soluçães \\
\hline F - Dimensão Relacionamento \\
\hline G - Dimensão Agregação de valor \\
\hline H - Dimensão Processos \\
\hline I - Dimensão Organização \\
\hline J - Dimensão Cadeia de fornecimento \\
\hline K - Dimensão Presença \\
\hline L - Dimensão Rede \\
\hline M - Dimensão Ambiência Inovadora \\
\hline Grau de inovação Global \\
\hline
\end{tabular}

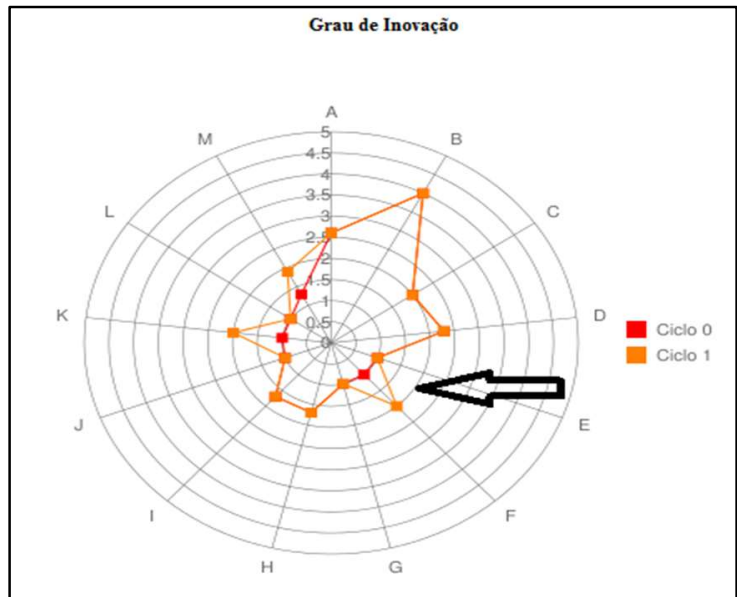

Figura 2: Modelo de ação concluída no T1.

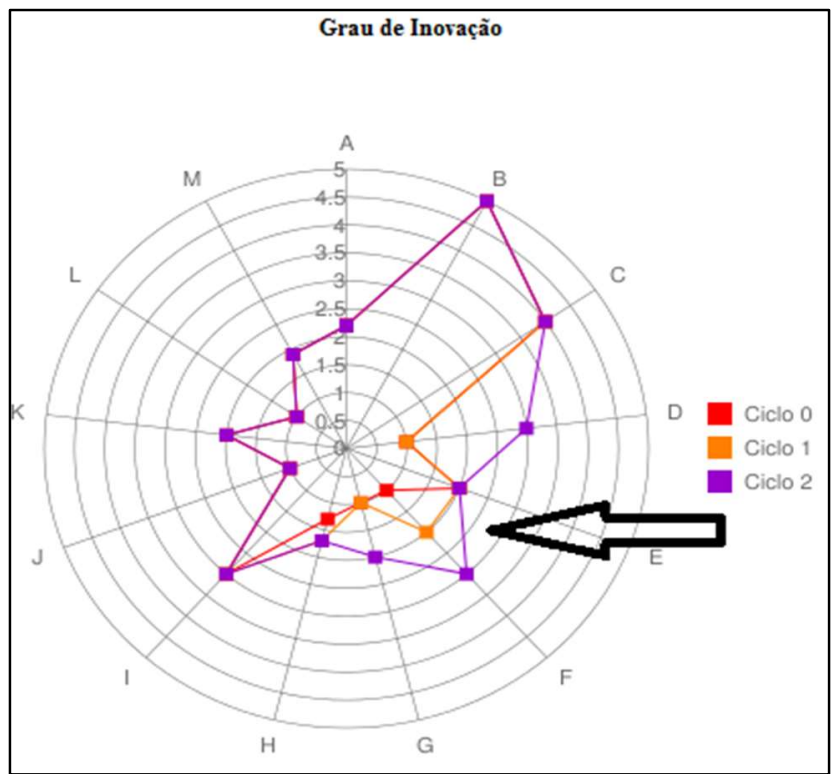

Figura 3: Modelo de ação concluída no T2.

Portanto, para fins de unificar a comparação, usaremos TF (Tempo Final) para demonstrar o resultado final de quando a ação foi concluída, que independe de ter sido concluída no T1 ou no T2. Na proposta de apresentar essas modalidades de inovação em marketing, os consumidores dos serviços não conhecem as possibilidades de fomento à inovação como fundos setoriais e constitucionais (RAINATTO et al., 
2020), o que dificulta a relação de ampliação da estrutura base para os consumidores de mídias.

\section{Radar da inovação}

O Radar de Inovação, conforme já citado no item 2.1, possui 13 dimensões. A dimensão que o presente artigo se propõe a analisar é a Dimensão Relacionamento.

Na dimensão a ser estudada, constam os seguintes itens: o item 17 - Facilidades e Amenidades - que avalia o esforço da empresa em criar uma imagem positiva junto aos clientes por meio da oferta de facilidades, amenidades e interfaces que melhorem a experiência dos clientes com a empresa; item 18 Informatização - que avalia a capacidade da empresa em usar de recursos de tecnologia de informação para aprimorar a relação com o cliente e elevar a experiência do mesmo. Em ambos os itens, a pontuação varia entre 1,3 e 5 .

No presente artigo, o foco das ações está direcionado para o item 18, uma vez que, as ações voltadas ao Marketing Digital, mais especificamente o desenvolvimento e reformulação de WebSites, impacta diretamente na Informatização.

\section{Empresas estudadas}

As dez empresas estudadas são indústrias, da cidade de Guarulhos, que fazem parte do universo das 40 empresas atendidas pelo Programa.

As empresas foram selecionadas para ser objeto de estudo pois foi identificada, diante dos resultados do relatório de devolutiva e de observação em campo, a necessidade de reformulação do site - para as empresas que possuíam sites inadequados, desatualizados e ineficazes -, ou de desenvolvimento de um novo site - para as empresas que ainda não possuíam esse recurso para se relacionar com o cliente -, sendo que, ambas as ações se enquadram no item 18, informatização, da dimensão relacionamento.

\section{RESULTADOS E DISCUSSÃO}

Os resultados apresentados no devolutiva do ciclo inicial mostraram que a maioria das empresas estudadas no presente artigo, possuíam a pontuação mínima na dimensão do relacionamento, uma vez que, de fato, não possuíam meios e ferramentas eficazes de se comunicar com os seus clientes e com o mercado.

Das dez empresas analisadas, seis tinham a pontuação mínima de 1,0, uma tinha a pontuação baixa de 2,0 e apenas três tinham a pontuação intermediaria de 3,0, no entanto, mesmo as que possuíam a pontuação intermediaria, falhavam no item de informatização, o que não as permitia ter uma pontuação ainda maior. Para todas as empresas, foi colocada uma ação no plano que gerasse impacto no item 18 , denominado Informatização, da dimensão Relacionamento do Radar de Inovação. Dessas, seis desenvolveram um WebSite, visto que não possuíam esse canal de comunicação, e as outras 4 reformularam um site que já existia, a fim de, melhorar o layout, corrigir informações errôneas e tornar o site mais completo e atrativo.

Em ambos os casos, a pontuação da dimensão de Relacionamento, demonstrada no relatório de 
devolutiva, apresentou diferença entre o ciclo inicial (momento anterior a implementação das ações) e o ciclo final (momento posterior a implementação da ação), justamente por conta do impacto das ações implantadas no item 18, informatização, como podemos analisar na tabela 1.

Tabela 1: Relação entre T0 e TF na dimensão Relacionamento.

\begin{tabular}{|l|l|l|}
\hline Empresas & T0 (Ciclo Inicial & TF (Ciclo Final) \\
\hline Empresa A & 1,0 & 2,0 \\
\hline Empresa B & 3,0 & 4,0 \\
\hline Empresa C & 1,0 & 3,0 \\
\hline Empresa D & 3,0 & 4,0 \\
\hline Empresa E & 1,0 & 2,0 \\
\hline Empresa F & 1,0 & 3,0 \\
\hline Empresa G & 3,0 & 4,0 \\
\hline Empresa H & 1,0 & 2,0 \\
\hline Empresa I & 1,0 & 2,0 \\
\hline Empresa J & 2,0 & 3,0 \\
\hline
\end{tabular}

É possível perceber que algumas empresas evoluíram mais do que um ponto de um ciclo para o outro, o que pode ser explicado por ações paralelas que foram realizadas como criação de catálogos, panfletos e redes sociais, e que também impactaram na dimensão de relacionamento, tanto no itens 17 - Facilidades e Amenidades -, como no item 18 - Informatização -, no entanto, vale ressaltar, que em todas as dez empresas as ações de criação e reformulação dos WebSites impactaram diretamente a evolução da dimensão de relacionamento ao alterar o item 18.

Essa informação permite analisar que, as empresas que mesmo após concluírem as ações e evoluírem no item 18 ficaram com a pontuação abaixo da média, que é de 3,0, precisam de mais ações no item de Facilidades e Amenidades e no próprio item de Informatização para conseguirem elevar a sua pontuação geral na dimensão Relacionamento.

\section{CONCLUSÕES}

Os resultados mostraram com nitidez que as ações de marketing digital e a presença virtual da empresa tem impacto no Relacionamento com o cliente. Tanto as empresas que já possuíam sites como as empresas que precisaram apenas melhorar sua presença virtual, conseguiram alterar o seu patamar na dimensão relacionamento do Radar de Inovação.

Obviamente, os efeitos de criar ou remodelar um site, vão muito além de uma simples mudança de pontuação no Radar de Inovação, porém, essa metodologia é eficaz no sentido de mostrar aos empresários que há a necessidade de realizar mudanças e também de apresentar os resultados que essas mudanças trouxeram.

$\mathrm{Na}$ indústria, muitas vezes o empresário está muito conectado aos mesmos processos e fluxos de sempre, ficando dessa forma, preso a uma rotina e por muitas vezes, até mesmo solitário na gestão da empresa. É um perfil que nem sempre compreendia a necessidade de ter uma presença virtual de qualidade e de como essa poderia influenciar nos negócios.

Além disso, muitos dos empresários atendidos tinham receio com a metodologia do programa por não ter familiaridade com o tema Inovação, e por acreditarem que não poderiam ser capazes de realizar uma 
determinada quantidade de ações em um prazo de tempo determinado. A metodologia ajuda a amenizar essas dúvidas a partir do momento em que mostra ao empresário que a pontuação dele pode melhorar e, principalmente, depois da execução, ao mostrar que a ação realizada alterou o patamar da empresa no Radar de Inovação na dimensão escolhida.

A satisfação de conseguir realizar uma ação, sentir seus resultados práticos nos negócios e quantificar a mudança a partir de uma metodologia voltada para resultados, é um grande impulso para que a empresa entenda que a inovação pode ser menos complicada na pratica do que pode parecer e cultive interesse por inovar constantemente, criando assim, uma cultura de inovação em sua empresa e um ambiente em que as mudanças são bem-vindas e frequentes.

Por essas razões o Programa ALI é tão importante, uma vez que, o acompanhamento personalizado é fundamental para que o empresário se sinta prestigiado e motivado em aplicar a metodologia e realizar as ações.

\section{REFERÊNCIAS}

ANDRADE, N.; RAINATTO, G. C.; SILVA, F. R.; SILVA NETO, G. R.; PASCHOAL, D. G. E.. Computational vision and business intelligence in the beauty segment: an analysis. Journal of Marketing Management, v.7, n.2, p.11-17, 2019.

FREIRE, K. M.. Design de experiência: uma forma de auxiliar as escolhas dos usuários. In: CONGRESSO BRASILEIRO DE PESQUISA E DESENVOLVIMENTO EM DESIGN, 8. Anais. São Paulo, 2008.

KOTLER, P.; ARMSTRONG, G.. Princípios de Marketing. São Paulo: Pearson Prentice Hall, 1998.

NICKELS, W. G.; WOOD, M. B.. Marketing: relacionamentos, qualidade, valor. Rio de Janeiro, 1999.

PRIDE, W. M.; FERREL, O. C.. Marketing: conceitos e estratégias. Rio de Janeiro: LTC, 2001.

RAINATTO, G. C.; SILVA, O. R.; ANDRADE, A. A.; ALMEIDA, E.;
CIPRIANI, P. D.; SABOYA, T.; CONCEIÇÃO, R. T.; BASTOS, W. F.. A new proposal for innovation indicators: A Study of the world's largest patent producing countries. International Journal of Business and Management, v.14, n.4, p.201-209, 2020. DOI: https://doi.org/10.5539/iibm.v15n4p201

RAINATTO, G.; SILVA, F.; ANDRADE, N.; RAINATTO, G.. Opções de Financiamento da Inovação. Revista Gestão \& Sustentabilidade, v.2, n.1, p.115-139, 2020.

SCHUMPETER, J. A.. The theory of economic development. Cambridge: Harvard University Press, 1934.

SILVA, C. E. L.; LIMA, G. B. A.; CARDOSO, R.; NARCIZO, R. B.. Inovação Sustentável: uma revisão bibliográfica. In: CONGRESSO NACIONAL DE EXCELÊNCIA EM GESTÃO, 6. Anais. Niterói, 2010.

VAZ, C. A.. Os 8 Os do Marketing Digital: O guia estratégico do Marketing Digital. São Paulo, 2011.

A CBPC - Companhia Brasileira de Produção Científica (CNPJ: 11.221.422/0001-03) detém os direitos materiais desta publicação. Os direitos referem-se à publicação do trabalho em qualquer parte do mundo, incluindo os direitos às renovações, expansões e disseminações da contribuição, bem como outros direitos subsidiários. Todos os trabalhos publicados eletronicamente poderão posteriormente ser publicados em coletâneas impressas sob coordenação da Sustenere Publishing, da Companhia Brasileira de Produção Científica e seus parceiros autorizados. Os (as) autores (as) preservam os direitos autorais, mas não têm permissão para a publicação da contribuição em outro meio, impresso ou digital, em português ou em tradução. 